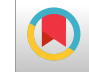

\title{
Apoptosis Induced by Viola odorata Extract in Human Glioblastoma Multiforme
}

\author{
Mansoureh Hashemi ${ }^{1}$, Zeinab Gharaylou ${ }^{2}$, Mohammad Reza Sepand ${ }^{3}$, Shokouh-Sadat Hamedi ${ }^{4}$, \\ Samira Raminfard (iD ${ }^{5}$, Maysam Alimohamadi ${ }^{6}$, Narjes Sherkatkhamene ${ }^{7}$, Leila Zarepour ${ }^{8}$ and \\ Mahmoudreza Hadjighassem ${ }^{6, *}$ \\ ${ }^{1}$ Functional Neurosurgery Research Center, Shahid Beheshti University of Medical Sciences, Tehran, Iran \\ ${ }^{2}$ International Campus, Tehran University of Medical Sciences, Tehran, Iran \\ ${ }^{3}$ Department of Toxicology and Pharmacology, Faculty of Pharmacology, Tehran University of Medical Sciences, Tehran, Iran \\ ${ }^{4}$ Department of Clinical Persian Pharmacy, School of Persian and Complementary Medicine, Mashhad University of Medical Sciences, Mashhad, Iran \\ ${ }^{5}$ Department of Neuroscience, School of Advanced Technologies in Medicine, Tehran University of Medical Sciences, Tehran, Iran \\ ${ }^{6}$ Brain and Spinal Cord Injury Research Center, Neuroscience Institute, Tehran University of Medical Sciences, Tehran, Iran \\ ${ }^{7}$ Research Center for Science and Technology in Science, Tehran University of Medical Sciences, Tehran, Iran \\ ${ }^{8}$ Physiology Research Center, Department of Physiology, Iran University of Medical Sciences, Tehran, Iran \\ "Corresponding author: Brain and Spinal Cord Injury Research Center, Neuroscience Institute, Tehran University of Medical Sciences, Tehran, Iran. Email: \\ mahmoudreza@hotmail.com \\ Received 2018 June 24; Revised 2018 October 08; Accepted 2018 October 17.
}

\begin{abstract}
Plant extracts contain useful components that could be considered in pharmacotherapy. Due to containing anticancer components such as phenol, cyclotide, and anthocyanins, Viola odorata (sweet violet) is one of the most important components used in cancer therapy. The current study aimed at examining antitumor activity and related mechanisms to $V$. odorata on primary culture of human glioblastoma multiforme (GBM). It was observed that survival rate of the obtained astrocytes from human GBM tumor decreased with $V$. odorata hydroalcoholic extract $(10-500 \mu \mathrm{g} / \mathrm{mL})$ in a dose- and time-dependent manner and DNA fragmentation happened in concentrations above $100 \mu \mathrm{g} / \mathrm{mL}$ of this extract. Further observations revealed that induced apoptosis activates mitochondrial death pathway, release cytochorome $\mathrm{C}$, and activates caspase-3. The current study findings revealed the effect mechanism of $V$. odorata extract and suggested its potential application in cancer therapy.
\end{abstract}

Keywords: Astrocyte, Apoptosis, Cell Survival, Glioblastoma Multiforme, Viola odorata

\section{Background}

Glioblastoma multiforme (GBM) is a primary cancerous tumor in the human central nervous system (CNS), which arises from astrocytes (1). GBM is known as the most aggressive tumor of astrocytoma with metastasis by proliferation and migration along blood vessels and white matter tracts in the brain (2). The study results show that adults are more prone to brain tumor than children. Despite advances in the current therapeutic procedures including surgery, radiotherapy, and chemotherapy, the median survival time is reported 12 to 15 months for patients (3). Different properties including genetic diversity, extensive neovascularization, and metastasis lead to the increase of resistance in tumor cells. These properties are the main causes of unsuccessfulness to treat patients with GBM (4). Cancer cell resistance can breakdown through activation of apoptotic cascade using various stimulators such as immunotherapy (5), hyperthermia (6), and herbal medicine
$(7,8)$. Herbal medicine is known as a plentiful source of pharmacological ingredients to treat cancer and tumors (8). Nowadays, various plant species are used in new drug synthesis (9). One of the most famous plants is Viola odorata from Violaceae family known as sweet violet. This plant contains active components such as cyclotide content (10), volatile oil, violin, odorutin, rutin, syanyn, bright pigment, methyl salicylate glycosides, and anthocyanins (11). Phenol, cyclotide, and anthocyanins are the most important metabolites with antioxidant and anticancer property (12, 13). Traditionally, V. odorata is used in anxiety, insomnia, hypertension, diuretic, and laxative disorders (14). This wide range of Violaceae family properties gained much attention to examine its effect on tumor cells. Previous studies show that the hydroalcoholic extract of $V$. tricolor has a potent antitumor activity against breast (15) and neuroblastoma tumors (16). The current study aimed at investigating the hydroalcoholic activity of extract on the cultured 
human GBM.

\section{Methods}

\subsection{Isolation and Culture of Astrocyte}

Resected GBM specimen obtained from patients that signed written consent letter were used in the current study. Pathological result of tumor specimen was confirmed by a pathologist. The isolation and culture of astrocyte from GBM were performed according to the previously described protocol of Hashemi et al. (17, 18). Samples were transferred to Hank balanced salt solution (HBSS, Gibco/Invitrogen) with 10\% - 15\% antibiotic/anti-mycotic (Gibco/Invitrogen). Small pieces of tissue were incubated 10 minutes with trypsin-EDTA $0.05 \%$ at $37^{\circ} \mathrm{C}$, then complete medium (the Dulbecco's modification of Eagle medium (DMEM)/F12 medium supplemented with 10\% fetal bovine serum (FBS) were used to inhibit trypsin activity. The cells were collected from medium by centrifuging for five minutes at $1000 \mathrm{rpm}$. Collected cells were cultured in DMEM/F12 medium containing $1 \%$ antibiotic/anti-mycotic and FBS $2 \%$, which increased gradually up to $10 \%$ during two weeks. The S100-beta was used as an astrocytic marker by immunocytochemistry.

\subsection{Immunocytochemistry}

Astrocyte cells $\left(5 \times 10^{4}\right.$ per well) were seeded in a 24-well culture plate; 24 hours later, wells were washed with phosphate-buffered saline (PBS). The cells were fixed with $4 \%$ paraformaldehyde for 20 minutes and washed three times with PBS. Cell membranes were permeabilized with $0.2 \%$ Triton X-100 for 15 minutes. Blocking was performed with $10 \%$ bovine serum albumin (BSA) for one hour after washing the cells with PBS. Then, the cells were incubated with primary antibody anti-S100-beta (SigmaAldrich, 1:100) overnight at $4^{\circ} \mathrm{C}$. Following three times washing with PBS, secondary antibody (fluorescein isothiocyanate conjugated goat anti-rabbit, Abcam; 1:200) was used for two hours at room temperature in darkness. Finally, inverted fluorescence microscopy (Olympus AX-70; Tokyo, Japan) was applied for detection.

\subsection{Collection of V. odorata and Preparation of the Hydroalco- holic Extract}

V. odorata with herbarium number 12855 was prepared in the Department of Herbarium and Pharmacognosy, School of Pharmacy, Mashhad University of Medical Sciences, Mashhad, Iran. In the Soxhlet apparatus, leaves and flowers were pulverized using water and alcohol; then the powder of violet $(100 \mathrm{~g}$ ) was mixed in $800 \mathrm{~mL}$ of $70 \%$ ethanol for 48 hours. The extract was filtered through a 0.106-mm membrane and dried by rotary in a water bath and the yield was dissolved in dimethyl sulfoxide (DMSO). The yield of the dried extract from starting materials was $18 \%$.

\subsection{MTT Test}

Astrocytes were seeded in a 96-well plate $\left(5 \times 10^{3}\right.$ cells per well). After 24 hours, the cells were treated with different concentrations of $V$. odorata hydroalcoholic extract $(10-500 \mu \mathrm{g} / \mathrm{mL})$ for 24,48 , and 72 hours, then the medium containing hydroalcoholic extract was removed and the cells were washed with PBS. The MTT solution, 3-(4, 5-dimethylthiazol-2-yl)-2, 5-diphenyltetrazolium bromide, in DMEM/F12 medium (100 $\mu$ L each well; $0.5 \mathrm{mg} / \mathrm{mL}$ ) was added in darkness. After incubation at $37^{\circ} \mathrm{C}$ for four hours, MTT solution was removed and formazan crystals dissolved in $100 \mu \mathrm{L}$ DMSO were added. The absorbance rate was measured at $570 \mathrm{~nm}$ with a microplate reader.

\subsection{Quantification of Apoptotic Cells by TUNEL}

Seeded astrocytes $\left(5 \times 10^{3}\right.$ cells per well in a 96-well microplate) were treated with various concentrations of hydroalcoholic extract of $V$. odorata $(10-500 \mu \mathrm{g} / \mathrm{mL})$ for 48 hours to identify apoptotic cells, in situ cell death detection kit (TUNEL) (Roche, Mannheim, Germany). Following 10 minutes of fixation using $4 \%$ paraformaldehyde and two minutes of permeabilization with Triton X-100, the cells were incubated with TUNEL reaction mixture for one hour. For positive and negative apoptosis control, cells were treated with ethanol 5\% and label solution, respectively. Fluorescent microscope (Olympus AX-70; Tokyo, Japan) was employed for TUNEL-positive cell counting in eight randomly selected fields from each culture.

\subsection{Real-Time Quantitative Reverse Transcription PCR}

Apoptosis was approved by the detection of BAX, Bcl2, and caspase 3 mRNA changes. Astrocyte cells $\left(1 \times 10^{6}\right.$ per well) were seeded in a 24-well culture plate and the cells were treated with $V$. odorata hydroalcoholic extract (10 $500 \mu \mathrm{g} / \mathrm{mL}$ ) for 48 hours. TriPure Isolation Reagent kit (Roche, Germany) was employed to isolate total RNA from astrocyte. First-strand cDNA synthesized $1 \mu \mathrm{g}$ of each RNA sample and incubated for five minutes at $85^{\circ} \mathrm{C}$ and $15 \mathrm{~min}$ utes at $37^{\circ} \mathrm{C}$ by the reverse transcriptase (Takara, Japan) with Random Hexamer, Oligo DT, and RNase inhibitor. RT-PCR was conducted using SYBR Premix Ex Taq II (Tli RNaseH Plus) (Takara, Japan) according to the manufacturer's instructions through the qRT-PCR detection system (Applied Biosystem, one step, RT- RCP Germany). The primer sequences were as follows: $\mathrm{BAX}$ forward primer (F) 5'-CAA ACT GGT GCT CAA GGC-3' and reverse primer (R) 5'-CAC AAA GAT GGT CAC GGT C-3'. Bcl-2 (F) 5'-GTA CTT 
AAA AAA TAC AAC ATC ACA G-3' and (R) 5'-CTT GAT TCT GGT GTT TCC C-3'; caspase 3 (F) 5'-CCGGGTCCTTCAAGGGATTC-3' and (R) 5'-GGTACTTGGTTGCTCAGGTTC-3', housekeeping hypoxanthine phosphoribosyltransferase1 (HPRT1) (F) 5'- CCTGGCGTCGTGATTAGTGA-3' and (R) 5'- AAGACGTTCAGTCC TGTCCAT-3'. All qRT-PCR assays were performed in triplicate. Gene expression levels were calculated according to the ${ }^{\Delta \Delta} \mathrm{Ct}$ method.

\subsection{Mitochondrial Preparation}

Isolation of mitochondria from astrocytes was performed by differential centrifugation $(19,20)$. Homogenized cells were centrifuged at $600 \mathrm{~g}$ for 10 minutes at $4^{\circ} \mathrm{C}$. The upper layer of fluid was removed and centrifuged at $7000 \mathrm{~g}$ for 10 minutes at $4^{\circ} \mathrm{C}$. The mitochondrial pellet was suspended in the isolation medium and centrifuged at $7000 \mathrm{~g}$ for 10 minutes at $4^{\circ} \mathrm{C}$. Finally, protein concentration was determined via bicinchoninic acid (BCA) assay as described by Smith et al. (21).

\subsubsection{Assessment of Mitochondrial ROS Level}

The mitochondrial ROS generation was quantified using dichloro-dihydro-fluorescein diacetate (DCFH-DA) as fluorescent dye. A non-fluorescent agent, DCFH, was made by cellular esterase through de-acetylation of the dye. Then DCFH was oxidized by ROS into DCF, a highly potent fluorescent compound, since ROS formation correlated directly with the fluorescence intensity. At first, the mitochondrial extracts were suspended in a respiration buffer with pH 7.4 containing sucrose $(0.32 \mathrm{mM})$, sodium succinate (5 mM), egtazic acid (EGTA) $(50 \mu \mathrm{M}), \mathrm{MgCl}_{2}(0.5 \mathrm{mM})$, Tris (10 mM), MOPS (20 mM), and $\mathrm{KH}_{2} \mathrm{PO}_{4}$ (0.1 mM) (20). Then, DCFH-DA $(10 \mu \mathrm{M})$ was added to the above mixture and incubated for 10 minutes. A fluorescence spectrophotometer with excitation at 488 and emission at $540 \mathrm{~nm}$ was applied to estimate DCF production.

\subsubsection{Assessment of the Mitochondrial Membrane Potential}

The cationic fluorescence dye rhodamine 123 easily absorbed and accumulated in the mitochondrial membrane. The MMP buffer contained sucrose $(220 \mathrm{mM})$, sodium succinate ( $5 \mathrm{mM})$, EGTA $(50 \mu \mathrm{M}), \mathrm{MgCl}_{2}(2 \mathrm{mM}), \mathrm{KH}_{2} \mathrm{PO}_{4}(5 \mathrm{mM})$, HEPES (4-(2-hydroxyethyl)-1-piperazineethanesulfonic acid) (10 mM), D-mannitol (68 $\mathrm{mM})$, rotenone $(2 \mu \mathrm{M})$, and $\mathrm{KCl}(10 \mathrm{mM})$ used to prepare mitochondrial fractions suspension. The suspension was treated for 60 minutes with rhodamine $123(10 \mu \mathrm{M})$. A fluorescence spectrophotometer with excitation at 490 and emission at $520 \mathrm{~nm}$ was applied to estimate the intensity (22).

\subsubsection{Assessment of Mitochondrial Swelling}

The swelling buffer contained sucrose $(70 \mathrm{mM})$, succinate ( $5 \mathrm{mM}$ ), Tris-phosphate (2 mM), HEPES (3 mM), mannitol $(230 \mathrm{mM})$, and rotenone $(1 \mu \mathrm{M})$ added to the mitochondrial fractions. The intensity of absorbance was read using an ELISA reader (Biotek 5, USA) at $540 \mathrm{~nm}$. The mitochondrial swelling rate was reversely proportional to absorbance intensity.

\subsubsection{Cytochrome C Release Assay}

At first, the 96-well microplate was precoated with a 75- $\mu$ L cytochrome $\mathrm{C}$ specific monoclonal antibody conjugated with horseradish peroxidase (HOURP). The astrocyte mitochondria, control and standard were added to each well and mixed gently with antibody. After two hours incubation, each well was aspirated and washed four times to remove any residual liquid. Then, the substrate solution (hydrogen peroxide plus tetramethylbenzidine; 100 $\mu \mathrm{L}$ ) was added into the wells and incubated for 30 minutes. Finally, stop solution $(100 \mu \mathrm{L})$ was applied to each well and the absorbance was read at $450 \mathrm{~nm}$.

\subsection{Statistical Analysis}

All data were shown as mean \pm standard error of the mean (SEM). Test results were obtained from three independent experiments. The statistical analysis of data was performed with SPSS version 20.0 using independent samples $t$ test followed by Turkey test. Pvalues $<0.05$ were considered statistically significant.

\section{Results}

\subsection{Identification of Isolated Astrocytes from Human GBM}

Astrocytes were observed with two different morphologies: Fibroblastic (slender, elongated, and spindleshaped) and epithelioid (large, with plentiful cytoplasm and interconnecting processes). Immunocytochemistry assessment showed that the cultured cells expressed astrocytes marker of S100-beta protein (Figure 1).

\subsection{Tumoricidal Effect of V. odorata Hydroalcoholic Extract}

The effect of $V$. odorata hydroalcoholic extract on cell survival of astrocyte was assessed by MTT assay. Cell survival significantly reduced in a dose- and time-dependent manner. Exposure of astrocytes to $10-500 \mu \mathrm{g} / \mathrm{mL}$ of the extract reduced cell survival. Based on the current study observations, a 48-hours treatment was selected as the optimal time for subsequent experiments (Figure 2). 

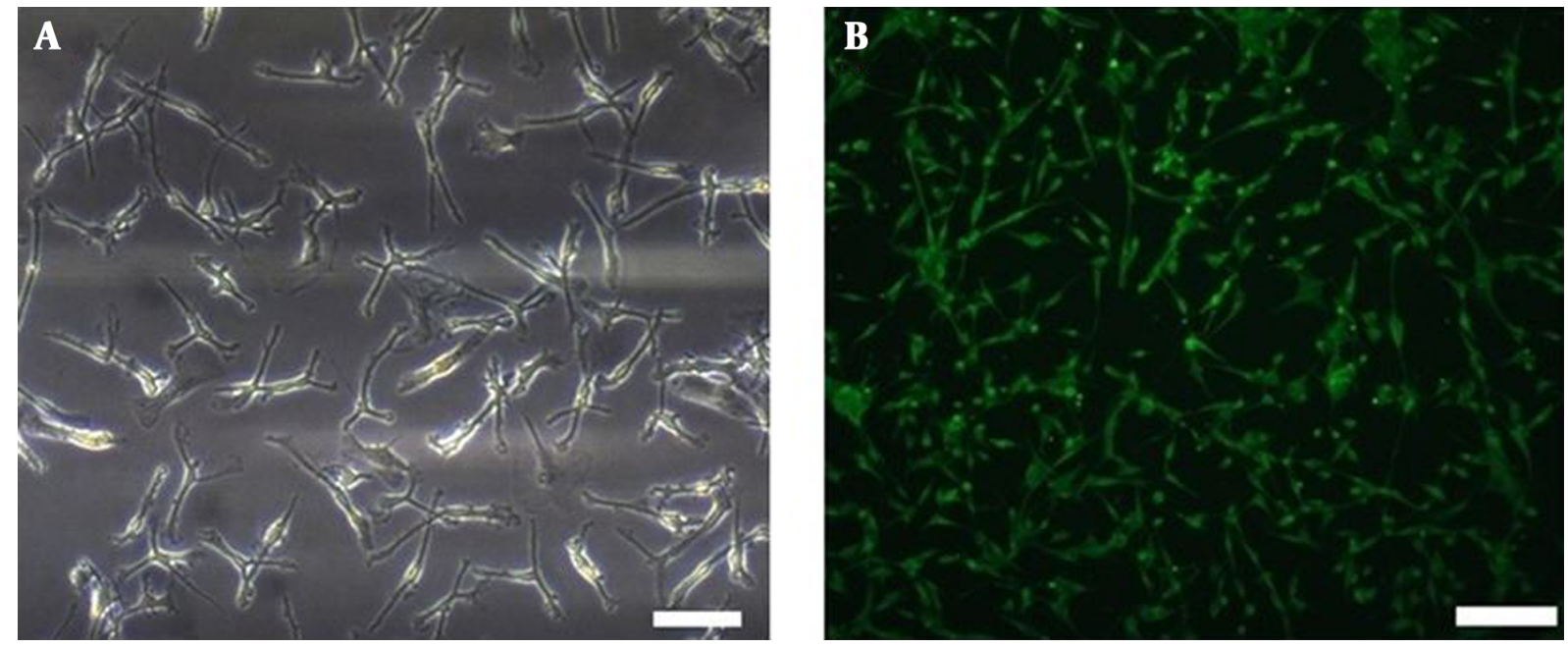

Figure 1. Morphological and S100-beta antigen observation of primary astrocyte derived from human glioblastoma multiform. A, Presentation of primary astrocyte derived from human glioblastoma after a 10-day culture. Scale bar: $50 \mu \mathrm{m}$; B, expression of S100-beta antigen was observed in the astrocytes thorough immunocytochemistry staining. Scale bar: $50 \mu \mathrm{m}$.

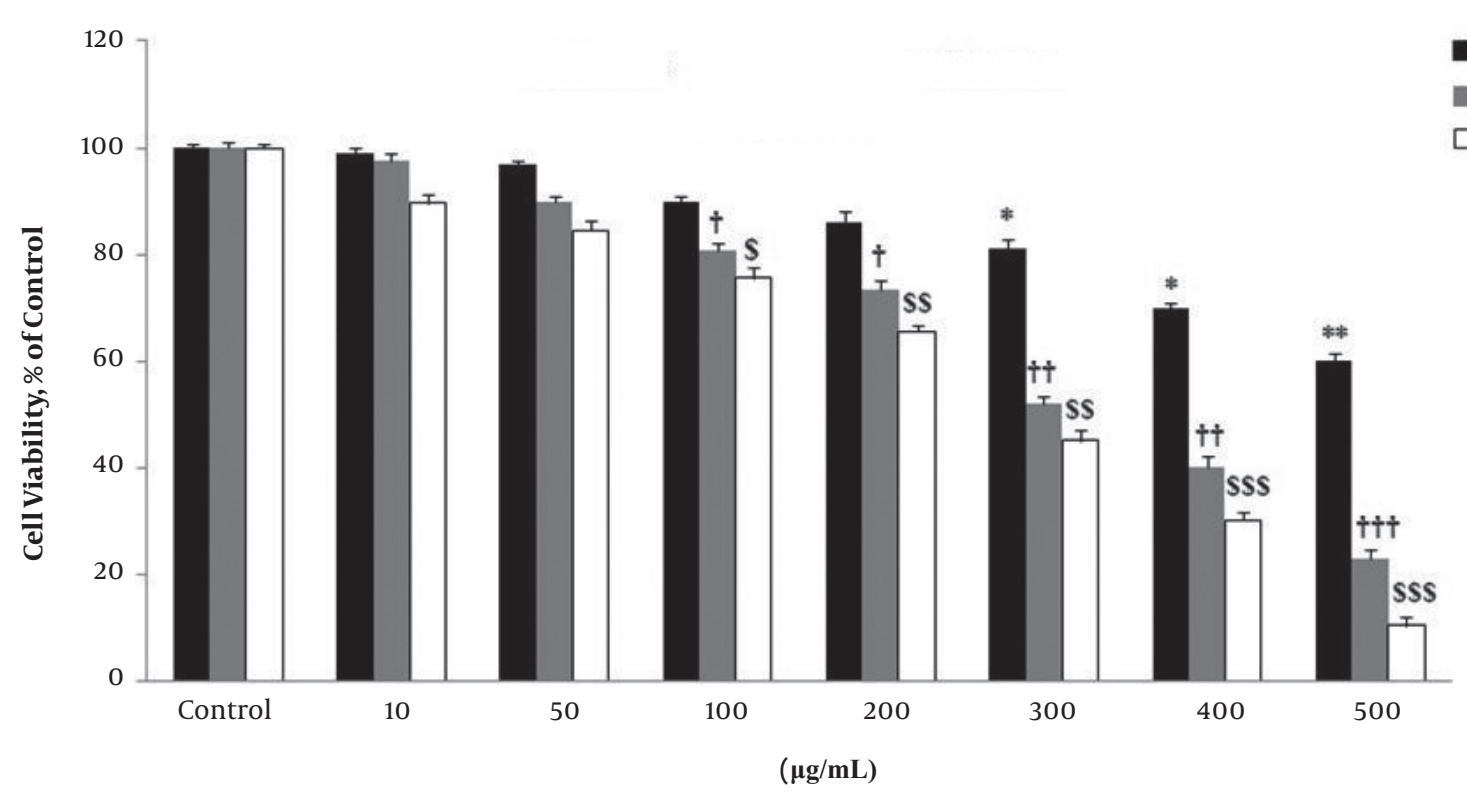

Figure 2. Tumoricidal effect of Viola odorata hydroalcoholic extract on astrocyte. Astrocytes were treated in various concentrations $(10-500 \mu \mathrm{g} / \mathrm{mL})$ for 24,48 , and 72 hours The survival rate of abstracts declined proportional to the concentration of $V$. odorata hydroalcoholic extract and exposure time. ${ }^{*} \mathrm{P}<0.05,{ }^{* *} \mathrm{P}<0.01, \uparrow \mathrm{P}<0.05, \dagger+\mathrm{P}<0.01, \mathrm{\dagger}+\mathrm{P}$ $<0.001, \$ \mathrm{P}<0.05, \$ \$ \mathrm{P}<0.01, \$ \$ \$ \mathrm{P}<0.001$

3.3. Levels of Induced Apoptosis in Astrocytes by V. odorata Hydroalcoholic Extract

Apoptosis was assessed in astrocytes with different concentrations of the extract (100 - 500 $\mu \mathrm{g} / \mathrm{mL})$. The current study observations showed that induction of apoptosis was dose-dependent. Apoptotic astrocytes observed brightly by TUNEL staining indicated fragmentation of nu-
24 Hours

48 Hours

$\square 72$ Hours 

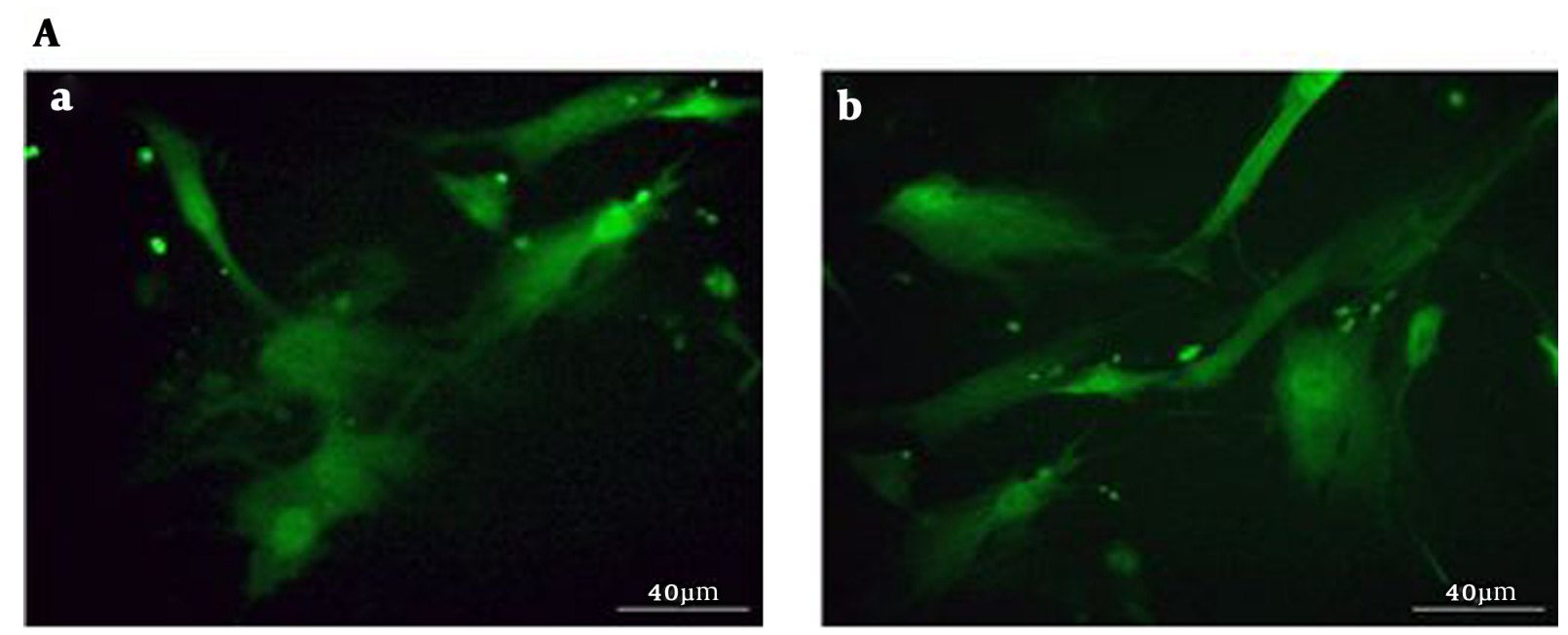

B

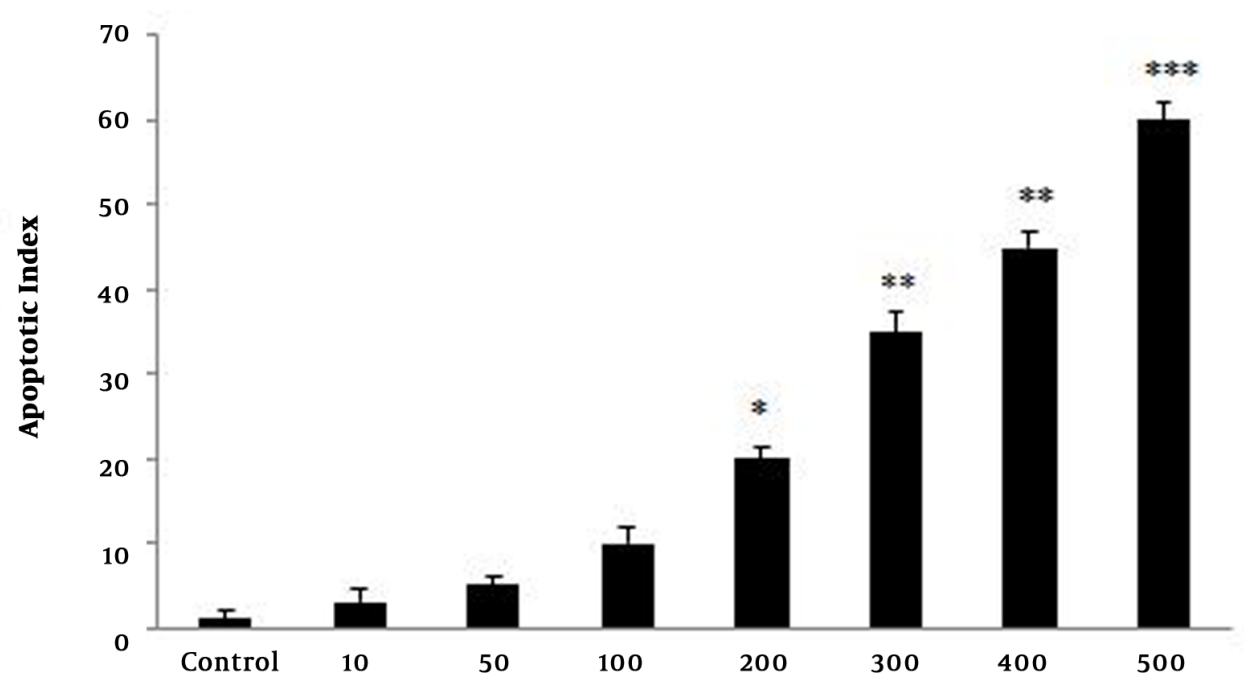

Figure 3. Presentation of apoptotic astrocytes by TUNEL assay. A, Apoptotic cells were labeled with TUNEL staining and cell nuclear was green. (a) Positive control and (b) apoptotic cells treated with Viola odorata hydroalcoholic extract, (scale bar $40 \mu \mathrm{m}$ ). B, Quantitative analysis of apoptotic index showed the treated astrocytes with various concentrations of $V$. odorata hydroalcoholic extract $(10-500 \mu \mathrm{g} / \mathrm{mL}) .{ }^{*} \mathrm{P}<0.05,{ }^{* *} \mathrm{P}<0.01,{ }^{* * *} \mathrm{P}<0.001$.

\subsection{Effect of V.odorata Hydroalcoholic Extract on Mitochondrial Parameters}

In order to find whether oxidative stress had a role in apoptosis induction, mitochondrial preparation was performed on treated and non-treated groups. It was identified that ROS production was significantly higher in mitochondria isolated from extract-treated groups and it was more prominent in concentrations above $100 \mu \mathrm{g} / \mathrm{mL}$ compared with those of the control group (Figure 4A).

It was further investigated whether ROS production accompanied by the mitochondrial permeability distur- bance. As an index of mitochondrial membrane permeability, it was revealed that absorbance reduction of isolated mitochondria was enhanced by the extract (Figure $4 \mathrm{~B})$.

Mitochondrial membrane potential $(\Delta \psi)$ is highly sensitive to functional changes of mitochondria. For this reason, mitochondrial inner membrane condition was evaluated via fluorescence dye of rhodamine 123. Incubation of astrocytes with $V$. odorata extract $(10-500 \mu \mathrm{g} / \mathrm{mL})$ for 48 hours led to significant increase in the percentage of mitochondrial membrane potential collapse $(\% \mathrm{D} \Psi \mathrm{m})$ in 
A

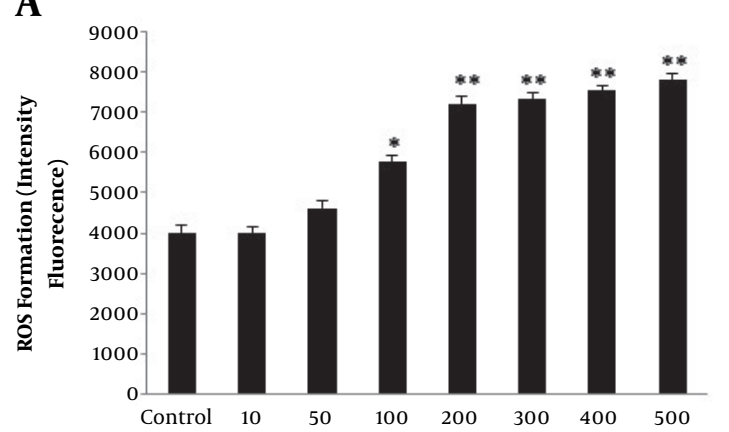

C

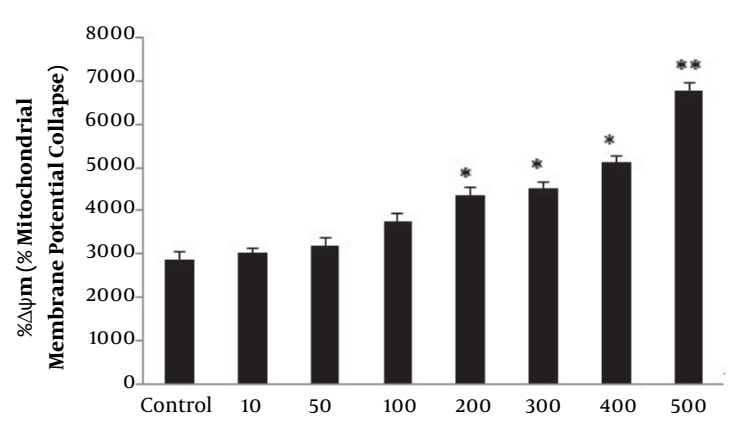

B

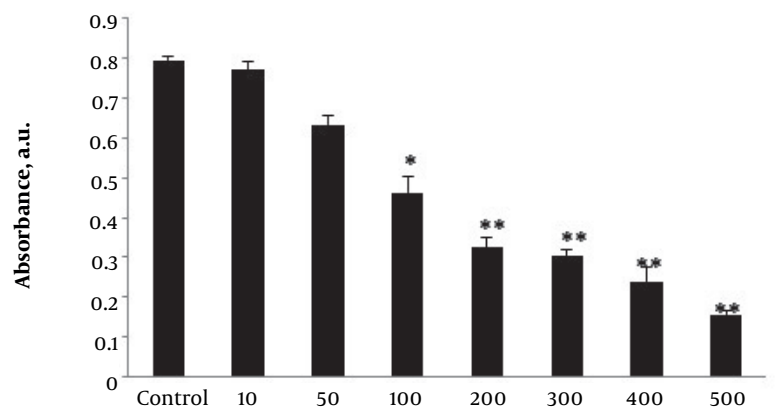

D

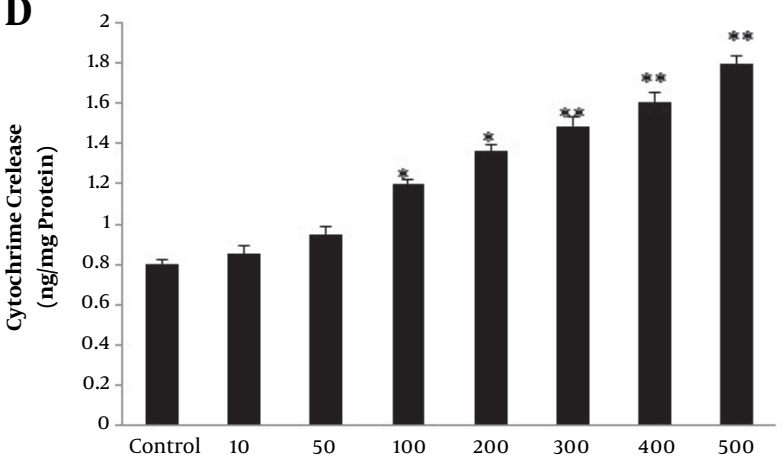

Figure 4. Effects of Viola odorata hydroalcoholic extract on astrocyte mitochondrial factors. A, ROS formation; B, progressive mitochondrial swelling; C, mitochondrial membrane potential collapse; $\mathrm{D}$, cytochourome $\mathrm{C}$ release from astrocyte mitochondria to cytosol ${ }^{*} \mathrm{P}<0.05,{ }^{* *} \mathrm{P}<0.01$.

a dose-dependent manner in groups treated with $>100$ $\mu \mathrm{g} / \mathrm{mL}$ (Figure 4C).

Instability of the mitochondrial membrane led to the increase of cytochrome $C$ release. The mitochondrial cytochrome $\mathrm{C}$ release was involved in triggering the cell death signaling cascade. The current study results indicated that the rate of cytochrome $C$ release had positive correlation with the concentration of the extract (Figure 4D).

\subsection{Level of Gene Expression of Apoptotic Markers in Astrocytes}

Since cytochrome $C$ release triggers apoptosis cascade, expression of pro-apoptotic genes were examined. The obtained results showed that $V$. odorata hydroalcoholic ex$\operatorname{tract}(10-500 \mu \mathrm{g} / \mathrm{mL})$ significantly increased pro-apoptotic Bax mRNA. While the level of anti-apoptotic Bcl-2 mRNA declined; suggesting that apoptosis induced via mitochondrial damages (intrinsic apoptotic pathway) (Figure 5A) and activation of caspase-3 in the treated cells (Figure 5B).

\section{Discussion}

Glioblastoma is a fast-growing astrocytoma that forms star-shaped glial cells (astrocytes). In the current study,
GBM derived astrocytes were obtained from patients undergoing the surgery. The purity of cells was assessed by the of S100-beta antigen (23). In the current study, total crude $V$. odorata hydroalcoholic extract was employed as a herbal medicine instead of specific components. Authors believe that the existence of all components may help the kinetic of the herbal drugs. The current study data showed that survival of primary astrocytes was derived from GBM inhibited by $V$. odorata. This effect was observed with hydroalcoholic extract of $V$. odorata at $>100$ $\mu \mathrm{g} / \mathrm{mL}$ (100 - $500 \mu \mathrm{g} / \mathrm{mL}$ ); while concentrations less than $100 \mu \mathrm{g} / \mathrm{mL}$ ( $0-50 \mu \mathrm{g} / \mathrm{mL})$ did not have a suppression role (24). Inducing or exacerbation of apoptosis is a useful technique to develop new therapies against cancer cells such as the use of cytotoxic factors in chemotherapy, radiation therapy, and, recently, herbal medicine (25). Apoptosis leads to DNA fragmentation (26). Two main pathways induced apoptosis in the cell; extrinsic pathway thorough activation of cell death receptor and intrinsic pathway via mitochondrial. Stimulants that change permeability of the mitochondrial membrane can trigger apoptosis by simplifying cytochourome $\mathrm{C}$ release. Following the release of cytochrome $C$, caspase $9 / 3$ signaling is activated $(27,28)$. The current study observations also revealed that 
A

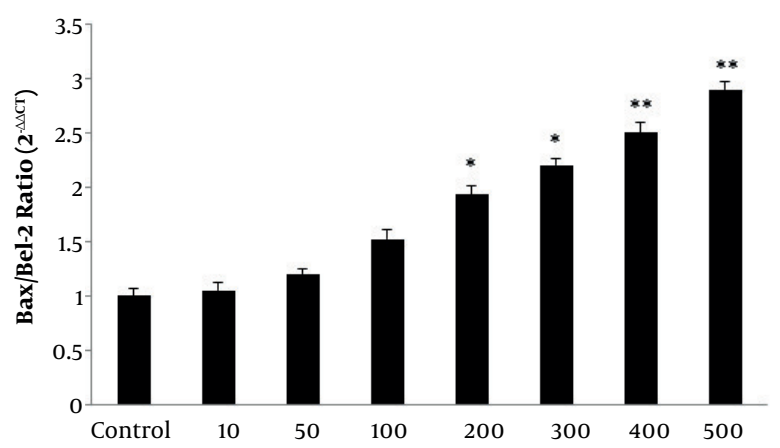

B

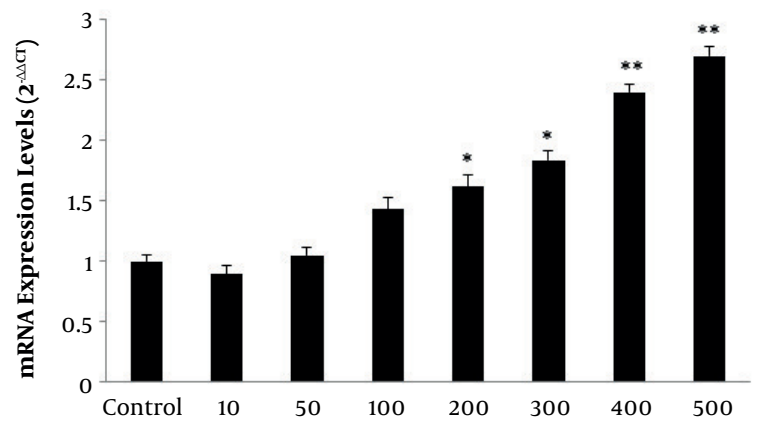

Figure 5. Effects of Viola odorata hydroalcoholic extract on astrocyte on apoptotic markers; qPCR analysis of caspase 3, Bax, and Bcl-2 mRNA expression in the astrocytes treated with various concentrations of $V$. odorata hydroalcoholic extract $(10-500 \mu \mathrm{g} / \mathrm{mL})$. Quantitative analysis of relative levels was revealed in A, Bax/Bcl-2 ratio and B, caspase-3. *P $<0.05$ and $^{* *} \mathrm{P}<0.01$.

changes in membrane potential of mitochondria induced by $V$. odorata extract was accompanied by the release of cytochourome C. Hydroalcoholic extract of $V$. odorata by increasing Bax expression increases the permeability of mitochondria membrane and ROS production, which is in line with the functional role of Bax. Besides, high levels of Bax expression leads to opening the mitochondrial permeability transition (MPT) pore, facilitating release of cytochrome Cinto cytosol, and swelling of mitochondria (29, 30). It was also observed that the expression of caspase 3 increased in GBM-derived cells treated with hydroalcoholic extract of $V$. odorata; suggesting that caspase 3 was activated as one of the enzymes of the primary executioner of apoptosis (31).

\subsection{Conclusion}

In conclusion, results of the current study showed that the total extraction of $V$. odorata can induce apoptosis in GBM-derived astrocytes by activation of intrinsic cell death pathway. Further studies using animal model of brain tumor should be conducted to assess the effect of this extract on GBM.

\section{Footnotes}

Authors' Contribution: Mansoureh Hashemi, drafting and writing of the manuscript, quantification of apoptotic cells by TUNEL; Zeinab Gharaylou, analyzing, and purification of all RNA, Mohammad Reza Sepand, assessment of mitochondrial ROS level, Shokouh-Sadat Hamedi, collection of Viola odorata plant and preparation of the hydroalcoholic extract, Samira Raminfard, study concept, interpretation of results; Leila Zarepour, statistical analysis; Narjes Sherkatkhamene, MTT assay; Maysam Alimohamadi, patient sample; Mahmoudreza Hadjighassem, project design and supervision, critical revision and submitted approval.

Conflict of Interests: The Authors declares that they have no conflicts of interest to this article.

Ethical Considerations: The study protocol approved by the Ethical committee of the Tehran University of Medical Sciences.

Funding/Support: The current study was supported by Brain and Spinal Cord Injury Research Center, Tehran University of Medical Sciences, Tehran, Iran.

\section{References}

1. Kleihues P, Louis DN, Scheithauer BW, Rorke LB, Reifenberger G, Burger PC, et al. The WHO classification of tumors of the nervous system.J Neuropathol Exp Neurol. 2002;61(3):215-25. discussion 226-9. doi: 10.1093/jnen/61.3.215. [PubMed: 11895036].

2. Giese A, Bjerkvig R, Berens ME, Westphal M. Cost of migration: Invasion of malignant gliomas and implications for treatment. J Clin Oncol. 2003;21(8):1624-36. doi: 10.1200/JCO.2003.05.063. [PubMed: 12697889].

3. Wen PY, Kesari S. Malignant gliomas in adults. $N$ Engl $J$ Med. 2008;359(5):492-507. doi: 10.1056/NEJMra0708126. [PubMed: 18669428].

4. Furnari FB, Fenton T, Bachoo RM, Mukasa A, Stommel JM, Stegh A, et al. Malignant astrocytic glioma: Genetics, biology, and paths to treatment. Genes Dev. 2007;21(21):2683-710. doi: 10.1101/gad.1596707. [PubMed: 17974913].

5. Chow KH, Gottschalk S. Cellular immunotherapy for high-grade glioma. Immunotherapy. 2011;3(3):423-34. doi: 10.2217/imt.10.110. [PubMed: 21395383]. [PubMed Central: PMC3130624].

6. Sun J, Guo M, Pang H, Qi J, Zhang J, Ge Y. Treatment of malignant glioma using hyperthermia. Neural Regen Res. 2013;8(29):2775-82. doi: 10.3969/j.issn.1673-5374.2013.29.009. [PubMed: 25206588]. [PubMed Central: PMC4145998].

7. Kamiyama H, Takano S, Ishikawa E, Tsuboi K, Matsumura A. Anti-angiogenic and immunomodulatory effect of the herbal medicine "Juzen-taiho-to" on malignant glioma. Biol Pharm Bull. 2005;28(11):2111-6. doi: 10.1248/bpb.28.2111. [PubMed: 16272699]. 
8. Itharat A, Houghton PJ, Eno-Amooquaye E, Burke PJ, Sampson JH, Raman A. In vitro cytotoxic activity of Thai medicinal plants used traditionally to treat cancer. J Ethnopharmacol. 2004;90(1):33-8. doi: 10.1016/j.jep.2003.09.014. [PubMed:14698505].

9. Limem-Ben Amor I, Boubaker J, Ben Sgaier M, Skandrani I, Bhouri W, Neffati A, et al. Phytochemistry and biological activities of Phlomis species. J Ethnopharmacol. 2009;125(2):183-202. doi: 10.1016/j.jep.2009.06.022. [PubMed: 19563875].

10. Trabi M, Svangard E, Herrmann A, Goransson U, Claeson P, Craik DJ, et al. Variations in cyclotide expression in viola species. J Nat Prod. 2004;67(5):806-10. doi:10.1021/np034068e. [PubMed: 15165141].

11. Saint-Lary L, Roy C, Paris JP, Tournayre P, Berdague JL, Thomas OP, et al. Volatile compounds of Viola odorata absolutes: Identification of odorant active markers to distinguish plants originating from France and Egypt. Chem Biodivers. 2014;11(6):843-60. doi: 10.1002/cbdv.201300387. [PubMed: 24934671].

12. Stojković D, Glamočlija J, Ćirić A, Šiljegović J, Nikolić M, Soković M. Free radical scavenging activity of Viola odorata water extracts. J Herbs Spices Med Plants. 2011;17(3):285-90. doi: 10.1080/10496475.2011.603588.

13. Esmaeili MA, Abagheri-Mahabadi N, Hashempour H, Farhadpour M, Gruber CW, Ghassempour A. Viola plant cyclotide vigno 5 induces mitochondria-mediated apoptosis via cytochrome $C$ release and caspases activation in cervical cancer cells. Fitoterapia. 2016;109:162-8. doi: 10.1016/j.fitote.2015.12.021. [PubMed: 26751970].

14. Mittal P, Gupta V, Goswami M, Thakur N, Bansal P. Phytochemical and pharmacological potential of viola odorata. Int J Pharmacogn. 2015;4:693. doi: 10.13040/ijpsr.0975-8232.ijp.

15. Sadeghnia HR, Ghorbani Hesari T, Mortazavian SM, Mousavi SH, Tayarani-Najaran Z, Ghorbani A. Viola tricolor induces apoptosis in cancer cells and exhibits antiangiogenic activity on chicken chorioallantoic membrane. Biomed Res Int. 2014;2014:625792. doi: 10.1155/2014/625792. [PubMed: 25243166]. [PubMed Central: PMC4163403].

16. Mortazavian SM, Ghorbani A. Antiproliferative effect of viola tricolor on neuroblastoma cells in vitro. Aust J Herbal Med. 2012;24(3):93-6.

17. Hashemi M, Hadjighassem M. Preparation of primary astrocyte culture derived from human glioblastoma multiforme specimen. Bio Protocol. 2017;7(8). doi: 10.21769/BioProtoc.2241.

18. Hashemi M, Fallah A, Aghayan HR, Arjmand B, Yazdani N, Verdi J, et al. A new approach in gene therapy of glioblastoma multiforme: $\mathrm{Hu}$ man olfactory ensheathing cells as a novel carrier for suicide gene delivery. Mol Neurobiol.2016;53(8):5118-28. doi: 10.1007/s12035-015-9412-y. [PubMed: 26395282].

19. Hosseini MJ, Shaki F, Ghazi-Khansari M, Pourahmad J. Toxicity of vanadium on isolated rat liver mitochondria: A new mechanistic approach. Metallomics. 2013;5(2):152-66. doi: 10.1039/c2mt20198d. [PubMed: 23306434].
20. Frezza C, Cipolat S, Scorrano L. Organelle isolation: Functional mitochondria from mouse liver, muscle and cultured fibroblasts. Nat Protoc. 2007;2(2):287-95. doi: 10.1038/nprot.2006.478. [PubMed 17406588].

21. Smith PK, Krohn RI, Hermanson GT, Mallia AK, Gartner FH, Provenzano MD, et al. Measurement of protein using bicinchoninic acid Anal Biochem. 1985;150(1):76-85. doi: 10.1016/0003-2697(85)90442-7. [PubMed: 3843705].

22. Sepand MR, Ghahremani MH, Razavi-Azarkhiavi K, Aghsami M, Rajabi J, Keshavarz-Bahaghighat $\mathrm{H}$, et al. Ellagic acid confers protection against gentamicin-induced oxidative damage, mitochondrial dysfunction and apoptosis-related nephrotoxicity.J Pharm Pharmacol. 2016;68(9):1222-32. doi: 10.1111/jphp.12589. [PubMed: 27364420].

23. Bao $\mathrm{S}, \mathrm{Wu} \mathrm{Q}$, McLendon RE, Hao $\mathrm{Y}$, Shi Q, Hjelmeland $\mathrm{AB}$, et al Glioma stem cells promote radioresistance by preferential activation of the DNA damage response. Nature. 2006;444(7120):756-60. doi 10.1038/nature05236. [PubMed: 17051156].

24. Yasuda Y, Tateishi N, Shimoda T, Satoh S, Ogitani E, Fujita S. Relationship between S10obeta and GFAP expression in astrocytes during infarction and glial scar formation after mild transient ischemia. Brain Res. 2004;1021(1):20-31. doi: 10.1016/j.brainres.2004.06.015. [PubMed 15328028].

25. Mousavi SH, Naghizade B, Pourgonabadi S, Ghorbani A. Protective effect of Viola tricolor and Viola odorata extracts on serum/glucose deprivation-induced neurotoxicity: Role of reactive oxygen species. Avicenna J Phytomed. 2016;6(4):434-41. [PubMed: 27516984]. [PubMed Central: PMC4967839].

26. Evan GI, Vousden KH. Proliferation, cell cycle and apoptosis in cancer. Nature. 2001;411(6835):342-8. doi: 10.1038/35077213. [PubMed 11357141].

27. Kasibhatla S, Tseng B. Why target apoptosis in cancer treatment? Mol Cancer Ther. 2003;2(6):573-80. [PubMed: 12813137].

28. Circu ML, Aw TY. Reactive oxygen species, cellular redox systems, and apoptosis. Free Radic Biol Med. 2010;48(6):749-62. doi: 10.1016/j.freeradbiomed.2009.12.022. [PubMed: 20045723]. [PubMed Central: PMC2823977].

29. dos Santos LV, Carvalho AL. Bcl-2 targeted-therapy for the treatment of head and neck squamous cell carcinoma. Recent Pat Anticancer Drug Discov. 2011;6(1):45-57. doi: 10.2174/157489211793980042. [PubMed: 21110823].

30. Saikumar P, Dong Z, Patel Y, Hall K, Hopfer U, Weinberg JM, et al. Role of hypoxia-induced Bax translocation and cytochrome $c$ release in reoxygenation injury. Oncogene. 1998;17(26):3401-15. doi: 10.1038/sj.onc.1202590. [PubMed: 10030664].

31. Garrido C, Galluzzi L, Brunet M, Puig PE, Didelot C, Kroemer G. Mechanisms of cytochrome c release from mitochondria. Cell Death Differ. 2006;13(9):1423-33. doi:10.1038/sj.cdd.4401950. [PubMed: 16676004]. 